Article

\title{
Expedition Cruising in the Canadian Arctic: Visitor Motives and the Influence of Education Programming on Knowledge, Attitudes, and Behaviours
}

\author{
Brittany Manley ${ }^{1}$, Statia Elliot ${ }^{1}$ and Shoshanah Jacobs ${ }^{2,3, *}$ \\ 1 School of Hospitality, Food \& Tourism Management, University of Guelph, Guelph, ON N1G 2W1, Canada; \\ brittany.manley@gmail.com (B.M.); statia@uoguelph.ca (S.E.) \\ 2 Department of Integrative Biology, University of Guelph, Guelph, ON N1G 2W1, Canada \\ 3 College of Biological Sciences, Office of Educational Scholarship and Practice, University of Guelph, Guelph, \\ ON N1G 2W1, Canada \\ * Correspondence: sjacob04@uoguelph.ca; Tel.: +1-519-824-4120 (ext. 58096)
}

Academic Editors: Machiel Lamers and Edward Huijbens

Received: 30 April 2017; Accepted: 19 June 2017; Published: 23 June 2017

\begin{abstract}
Cruising is a segment of tourism that is increasing at a faster rate than other kinds of leisure travel, especially in the Arctic region. Due to changing environmental conditions in recent years, cruise ships have been able to access more regions of the Arctic for a longer operating season. We investigated the cruiser motivations for polar expedition cruising and the educational dimensions of expedition cruising. Motivations of cruisers were identified using entrance surveys prior to embarking on four separate itineraries $(n=144)$. We conducted semi-structured interviews, $n=22)$, made participant observations while on board the vessel for one trip to support survey findings, and followed up with a post-trip survey to assess attitudinal changes $(n=92)$. We found that, unlike mainstream cruisers, expedition cruisers are motivated by opportunities for novel experience and for learning. Subsequently, the educational programming offered by expedition cruise companies is an important component of the cruise experience. We found that this programming has positively impacted cruiser attitudes, behaviours, and knowledge post-cruise. These findings will encourage cruise companies to improve their educational offerings (i.e., preparedness, program quality, level of engagement) to meet the expectations of their clientele, thereby transferring critical knowledge of environmental stewardship.
\end{abstract}

Keywords: Arctic; expedition cruising; knowledge transfer; eco-tourism

\section{Introduction}

Cruising is a high growth segment of tourism that is increasing faster than other formats of leisure travel [1], particularly in the Arctic and Antarctic regions in the past two decades [2,3]. Due to increasingly milder environmental conditions and the subsequent earlier breakup of ice [4-7], cruise ships are able to access more of the polar regions for a longer operating season ([8], but see [2]) and growing participation in "last chance tourism" is projected to cause a further increase in visitors [9-16]. According to the International Association of Antarctica Tour Operators (IAATO), the 2016-2017 Antarctic cruise operating seasons saw 44,402 tourists compared to 7547 in 2002-2003 [17], a $580 \%$ increase.

Expedition cruising as we know it today came to the Arctic in 1984 with the MS Explorer [18,19]. Expedition cruising is unique compared to other forms of mainstream cruising; with relatively small ships that hold up to 200 cruisers, the specific intent is to offer rich experiences with shore landings via inflatable boats that access remote locations. Onboard programming focuses on a comprehensive 
educational experience, usually for a highly educated clientele. Expedition cruising is a specialized niche requiring considerations beyond the cruiser experience. Operators are required to consider the unique challenges of passenger and ship safety, ship logistics, environmental sustainability, and-of specific interest here-knowledge transfer and education of the cruisers. While research has studied cruising from an environmental and operational perspective (i.e., [20]), few studies have addressed the motivations of cruisers to embark on expedition cruising and the educational dimensions (but see [21,22]).

Based upon internal cruiser exit surveys, expedition cruising companies assume that cruisers are motivated to buy a ticket because of the educational aspects of the proposed itineraries, in addition to the opportunity to explore an extreme environment and see the expanse of ice before it melts. Consequently, Arctic and Antarctic expedition cruise lines have developed a range of educational programs to address the presumed desire of cruisers for an educational and immersive experience. Pre-embarkation packages might include a variety of resources including company-specific handbooks and websites and suggested reading lists. On board, programs of specialized lectures on destination-appropriate topics are offered during time at sea or poor weather conditions. Guides are employed to lead excursions on shore such as guided walks and interpretation with flora and fauna identification. Whether at sea or on land, the guides are constantly scanning for wildlife. Upon disembarkation cruisers often leave with packages of information and photographs provided by the cruise company.

While educational programming is offered in practice, there is little research on the motivations and expectations of the cruisers, or the effectiveness of knowledge transfer from the programming to the cruiser. Therefore, we investigated the motivations of cruisers to take an Arctic expedition cruise and examined the impacts of the educational programming on cruisers' subsequent attitudes and conservation behaviours.

\subsection{Motivations}

In the 30 years that expedition cruise ships have been travelling to Canada's Arctic regions [18,23], there has been a steady increase in the companies involved and itineraries offered [13]. A few studies have investigated the motivations of cruise passengers more generally [24,25], but none have studied the motivations of cruisers who choose expedition cruises to the Arctic.

Studies on motivations for cruising have focused on factors such as pleasure, control, and novelty [26,27], and it has been found that pleasure is correlated with cruisers' value perceptions, that cruisers are swayed by social influences, and that cruisers are loyal to a company from which they have previously purchased trips [28]. Mainstream cruisers are motivated by the opportunity for relaxation, enhancement of kinship relationships or friendships, and convenience [24].

While participating in educational programs is not a top motivating factor in mainstream cruising, Hung and Petrick (2011) suggest that cruise ship programming should include opportunities to learn and discover. They recommend specific activities such as "Be a chef/captain/cast member today", or shipboard tours in addition to off-ship activities offered at the various ports of call. While it is noteworthy that mainstream cruisers are often interested in learning and discovery, it is likely that their educational expectations are different from those of the expedition cruisers.

We hypothesize that learning and discovery are the primary motivators for Arctic expedition cruisers and is based upon the observation that expedition cruise companies have focused on nature-based excursions that are included in the price of the cruise package and the offering of educational programming.

\subsection{Attitude Change Theory Model}

The Elaboration Likelihood Model (ELM) was used as the basis for this research because this is the predominant method used within the educational tourism context [21,29] and it is used to investigate how a persuasive message can change attitudes. 
There are two routes of persuasion: central processing and peripheral processing [30]. The route of persuasion that the cruiser takes when involved with an educational program is important to map because it predicts the strength of change in attitude [29]. Central processing refers to the individual being an active participant such that $\mathrm{s} /$ he would need to contemplate the message from the educational programming, consider the implications, and relate information to her/his own knowledge and values. Motivation and ability are the two main influences that would dictate the cruiser's route of attitude change. If the topic is not of interest to the cruiser then there is a lack of motivation to achieve central processing. If the educational program is poorly designed and the message is unclear, the cruiser will be unable to achieve central processing [29]. However, if the message is clear, well presented and meaningful to the cruiser, $\mathrm{s} /$ he can then be motivated to process the information and will have a high level of cognitive involvement. Petty et al. (1995) found that long-term and short-term attitude changes are often developed from the central route and peripheral route, respectively [31].

The second route is relevant when the cruiser has little or no interest in the subject. S/he will focus on everything but the actual message such as: qualifications of the guide, whether the tone of the guide's voice and body language demonstrates authority, and/or the degree to which the messages are supported by credible sources. In this context, the cruiser decides if the information offered through the educational programming is worth accepting.

ELM relates best to understanding Arctic cruisers' attitudes toward the environment and the impacts of education related to the cruise experience because it posits that the more the information regarding pro-environmental attitude provokes the cruiser to think about their own attitudes, the more they create personal meanings about the topic. It therefore predicts that the cruiser is more likely to act on the information presented [21].

\subsection{Expedition Cruise Ships}

Expedition cruise ships can carry up to 200 cruisers, and offer an educational experience delivered by discipline-specific guides on board [21]. An important feature of expedition cruising is that companies search for new and unvisited locations with either a natural or cultural appeal ([32], p. 251) such that cruisers have the opportunity to develop a deeper connection with a novel environment $[29,33]$. In the Arctic, this is achieved by Zodiac boat trips to view wildlife, kayak excursions in sea ice, hikes on the tundra, and cultural programming offered in remote ports of call. The quality of the interaction between the environment and the cruiser therefore varies depending on the individual's personality, the effectiveness of the guide [34], and the presence of wildlife.

This study explored four questions:

Q1. Are motivational factors for engaging in Arctic expedition cruising different from other cruising motivations?

Due to the highly specialized nature of expedition cruising, we hypothesized that expedition cruising attracts cruisers with different motivations than mainstream cruises. We predicted that expedition cruisers are more motivated by educational factors.

Q2. What on-ship cruising activities is the expedition company offering to meet presumed cruiser's educational expectations?

Q3. Do on-ship cruising activities for cruisers correspond to pre-cruise motivations?

Q4. What is the impact of the educational experiences on attitudes post-cruise?

It was hypothesized that cruiser engagement with destination-based educational programming has an effect on attitudes and behaviours. Based on the learning-focused motivations and expectations of the cruiser, and the onboard multi-day exposure to the Arctic environment, it was predicted that some knowledge will be retained post-cruise and will result in modified environmental behaviour. 


\section{Methods}

We investigated the motivations, engagement with the educational programming, and subsequent knowledge transfer, attitude changes, and behavioural changes of expedition cruisers on an Arctic expedition cruise ship within the region of Nunavut, Canada and western Greenland during the 2014 summer sailing season. A research ethics approval certificate was received for all described protocols (see Supplementary Materials). The expedition cruise company Adventure Canada was selected because it is a Canadian cruise company that sails within the preferred locations and this increased the probability of contact with English-speaking cruisers as research participants. Adventure Canada provided a reduced rate for room and board for one of the researchers to conduct cruiser interviews and act as a participant observer. Pre-cruise surveys $(n=383)$ were distributed to cruisers on each of the four Adventure Canada trips. Post-cruise surveys $(n=272)$ were sent electronically three months after the trip. Three months was the selected timeframe to allow participants to return to their daily routines while still feeling a sense of group belonging to the pool of research participants. This time frame was also used in the Powell's 2008 Antarctic expedition study [35].

\subsection{Pre-Cruise Survey_Cruiser Motivations and Current Knowledge and Attitudes}

A pre-cruise survey was distributed to expedition cruisers while on board the charter flight at the beginning of their itinerary. This survey assessed motivations, knowledge, and attitudes about the Arctic and resource management, general views about the natural environment, and engagement in environmentally conscious behaviours. The specific factors assessed and the questions asked were based upon Powell's 2008 study on Antarctic expedition cruisers [35]. Modifications were made when necessary to reflect the difference in destination. Our survey tools are available in the Supplementary Materials. Of the 383 surveys distributed to potential participants, 144 pre-trip surveys were completed and returned for analysis (38\% response rate).

\subsection{Assessment of Educational Programming}

Information relating to the educational programming was collected via participant observation. This methodology, and the research generally, was introduced to all guides and cruisers during the technical stop of the charter flight. Cruisers received a letter of information, consent form, and pre-cruise survey. All cruisers and resource staff were informed of their right to be excluded from observation and from the study. A researcher attended all programming, excursions, and participated in many small group conversations while on board. Note taking was used to record information. This was done discreetly during the programming or immediately following the activity so as not to disrupt the cruiser experience. Being on board allowed the researcher to develop a relationship of trust with the cruisers and guides because they travelled together, ate together, and shared the same space for 10 days. This allowed the cruisers and guides to become accustomed to the researcher aboard and understand the intentions of the study. The educational programming offered by the company was recorded and characterized according to the location offered, duration, and nature of the offering.

\subsection{Semi-Structured Interviews with Cruisers}

The researcher conducted open-ended, semi-structured interviews with participants randomly selected from the ship's manifest near the end of the expedition to obtain detailed insight about the cruiser's experience (see Supplementary Materials). To ensure the sample of interviewed cruises was representative, the researcher interviewed 14 cruisers [36], which was also the maximum number that could be interviewed given the time constraint. Participants were asked to share how they felt about the educational programming on board and what effect the presentations had on their attitudes about various topics. The analysis looked at features of the educational programming and explored what potential benefits were likely. Finally, the interviews elucidated which aspects of the programming had personal significance to the cruisers and whether or not this changed their attitudes. 


\subsection{Semi-Structured Interviews with Guides}

During the 2014 Arctic expedition season, the expedition company employed between 12 and 15 expedition guides per itinerary. The guides varied in specialization including historian, geologist, culturalist, naturalist, or archaeologist. The researcher interviewed the eight guides who were responsible for topics related specifically to the natural environment (see Supplementary Materials). The data collected were used to help answer both the second and third research questions.

\subsection{Cruiser Interaction with the Educational Programming}

Expeditions to the Arctic offer a wide variety of educational themed activities to appeal to the cruisers and guides and cruisers interacted regularly. Observational data on guide interpreted information were collected during presentations and daily meetings. The researcher specifically observed the level of engagement that the cruisers had with the educational programming and guides by documenting the number of participants per activity and the frequency and quality of the questions posed during lecture sessions relating to the environment. A manifest content analysis of the questions posed during lecture sessions was measured against an adapted Bloom's Taxonomy scale [37].

\subsection{Post-Trip Survey: Effectiveness of Knowledge Transfer and Impact of the Expedition}

All cruisers were sent a link to a post-cruise survey three to four months after their cruise (see Supplemental Material). A modified Dillman (2000) approach was used [38]. This consisted of a cover letter with the survey, a subsequent email sent out three weeks after the initial email and a final reminder email to non-respondents five weeks after initial contact. The researcher did not collect email addresses from the pre-trip survey - the expedition company used their database to email each cruiser on behalf of the researcher using software to show the researcher's email address as the sender. Ninety-two cruisers completed the post-cruise survey that was used to determine whether there had been changes in cruiser attitudes. Therefore, it consisted of the same questions asked in the pre-cruise survey. Two sections were added to gain further information on the cruisers knowledge gain and educational impact from the expedition.

To better understand the educational benefits of participation in an Arctic expedition, cruisers were asked to self-report knowledge gain in five areas. The questions in this section have been adapted from Powell's (2008) survey with the addition of ornithology [35].

In an open-ended question, the post-cruise survey asked cruisers to share, what impact the expedition had on them.

\subsection{Data Analysis}

NVivo was used for the qualitative data analysis that required coding. All returned surveys were coded and the data were entered for quantitative analysis using the statistical program SPSS (Statistical Package for the Social Sciences). $T$ tests were used to determine whether there were significant differences in means and $G$ tests were used to determine whether there were significant differences in distributions. Statistical significance was identified at $p<0.05$.

\section{Results}

\subsection{Arctic Cruiser Profile}

Most of the participants were Canadian or American, living in large urban areas, between the ages of 61 and 80 years old, with post-secondary education. Most were inexperienced travellers to the Arctic but had previously participated in nature-based travel (see Table 1). 
Table 1. Summary of Arctic visitor profile $(n=144)$.

\begin{tabular}{cc}
\hline Demographic Variable & Summary \\
\hline Gender & $56.9 \%$ female, $42.4 \%$ male \\
Age & Mean age is 61-70 years \\
Previous Arctic Experience & $43.8 \%$ of participants had participated in an Arctic tour before \\
Previous Nature experience & $\begin{array}{c}25.7 \% \text { of participants had not participated in a nature trip before. The mean } \\
\text { number of previous nature tours is } 4.33 .6 \% \text { had participated in } 4 \text { or more } \\
\text { Residence Description }\end{array}$ \\
Country of citizenship & $57.7 \%$ of participants reside in a city or suburb \\
Formal education & $88.9 \%$ of participants live in Canada \\
& graduate from professional or graduate program \\
\hline
\end{tabular}

Q1. Are motivational factors for buying an Arctic expedition cruise different from other cruising motivations?

Motivational factors for buying a ticket for an Arctic expedition are different from the motivations associated with mainstream cruising motivations. "Seeing a beautiful landscape" and "seeing beautiful and unique wildlife" are the most common motivators for cruisers, with a combined $89.6 \%$ and $88.2 \%$, respectively, of cruisers identifying it as being either extremely important or very important. The third greatest motivator is "exploring new places" with a combined percentage of $86.1 \%$ (extremely important and very important). An additional motivation that is worth noting is "Learning about the natural history of the Arctic", with a combined percentage of $72.2 \%$ (extremely important and very important). The item with the lowest reported motivation was "Socializing with friends and family" (see Table 2).

In Hung and Petrick's (2011) study of motivations to cruise, they found "escape and relaxation" to be the strongest motivator, contributing the most to intentions to cruise [24]. In addition, in-depth interviews of participants did not report "exploration and education" as a motivation. The main motivations for expedition cruisers are therefore different compared to mainstream cruisers. Expedition cruisers are interested in being immersed within the Arctic environment; they want to learn, experience, and see the landscape and wildlife that are unique to the area.

\subsection{Open-Ended Survey Question}

To more fully understand cruiser motivations, an open-ended question asked: "Please explain in your own words why you chose to go on this expedition". The responses are categorized into four main motivational traits: learning/discovery, novelty/thrill, social recognition/prestige, and escape/relaxation with 15 sub-traits, for a total of 19 categories (Table 3-top three motivation categories identified).

In support of the quantitative findings, these responses indicate experiencing the landscape as the prime motivation to travel in the Arctic. What also emerges is the extent of the knowledge and previous travel experience held by expedition cruisers. Some participants mentioned a specific location: "most especially to see the Ilulissat Ice field" (AS-9) or referenced a specific landscape feature such as icebergs: "more iceberg scenery" (AS-23) and "to see the natural environment—wildlife, icebergs" (Q-80).

Responses also indicated that seeing Arctic wildlife was a primary motivation to visit the Arctic. A number of the responses were general, such as: "to see the wildlife" (AS-6) and: "to experience the wildlife" (AS-8). However, many responses referred to specific animals: "To see unusual wildlife like narwhals and polar bears" (AS-9); "I chose the trip to see the Arctic-hoping to see whales, muskoxen and polar bears" (Q-94); and "Bird watching" (Q-107). 
Table 2. Percent distribution of importance for 14 possible cruiser motivations for Arctic cruising (pre-trip survey; $n=144$ ).

\begin{tabular}{|c|c|c|c|c|c|c|c|c|}
\hline Motivation & $\begin{array}{c}\text { Mean * } \\
\text { (Out of 7) }\end{array}$ & $\begin{array}{l}\text { Extremely } \\
\text { Important }\end{array}$ & $\begin{array}{c}\text { Very } \\
\text { Important }\end{array}$ & Important & $\begin{array}{l}\text { Slightly } \\
\text { Important }\end{array}$ & $\begin{array}{l}\text { Not Very } \\
\text { Important }\end{array}$ & $\begin{array}{l}\text { Not at All } \\
\text { Important }\end{array}$ & $\begin{array}{c}\text { No } \\
\text { Opinion }\end{array}$ \\
\hline Seeing a beautiful landscape & 6.4 & 59.7 & 29.9 & 8.3 & 1.4 & 0.7 & 0.0 & 0.0 \\
\hline Seeing unique wildlife & 6.4 & 57.6 & 28.5 & 11.8 & 1.4 & 0.0 & 0.0 & 0.0 \\
\hline Exploring new places & 6.4 & 57.6 & 28.5 & 11.8 & 1.4 & 0.0 & 0.0 & 1.4 \\
\hline Seeing beautiful or interesting wildlife & 6.4 & 54.2 & 31.9 & 12.5 & 1.4 & 0.0 & 0.0 & 0.0 \\
\hline Learning about the natural history of the Arctic & 6.1 & 44.4 & 27.8 & 22.2 & 4.9 & 0.7 & 0.0 & 0.0 \\
\hline Learning about the human history of the Arctic & 5.9 & 40.6 & 25.9 & 24.5 & 8.4 & 0.0 & 0.7 & 0.0 \\
\hline Adventuring in the wilderness & 5.8 & 38.9 & 22.9 & 27.8 & 8.3 & 1.4 & 0.7 & 0.0 \\
\hline Learning about environmental issues and conservation & 5.6 & 29.2 & 31.3 & 26.4 & 9.0 & 2.8 & 1.4 & 0.0 \\
\hline Seeing the Arctic before it melts away & 5.5 & 38.5 & 17.5 & 24.5 & 11.2 & 2.1 & 3.5 & 5.6 \\
\hline Capturing photographs & 5.2 & 28.7 & 23.1 & 23.8 & 15.4 & 4.2 & 4.2 & 1.4 \\
\hline Experiencing a spiritual connection with nature & 4.6 & 18.3 & 19.0 & 25.4 & 14.8 & 9.2 & 9.2 & 6.9 \\
\hline Following in the footsteps of the great explores & 4.4 & 18.9 & 12.6 & 25.2 & 26.6 & 11.9 & 4.2 & 1.4 \\
\hline Relaxing \& escaping from everyday life & 4.1 & 8.4 & 11.9 & 34.3 & 20.3 & 12.6 & 10.5 & 4.2 \\
\hline Socializing with family and friends & 3.3 & 11.2 & 7.0 & 19.6 & 12.6 & 14.7 & 32.9 & 4.2 \\
\hline
\end{tabular}

* Scale: 7 = Extremely important to $1=$ not at all important. 
Table 3. Top expedition cruiser motivations for Arctic expedition cruising $(n=144)$ identified in an open-ended survey question. Some examples provided.

\begin{tabular}{ll}
\hline \multirow{3}{*}{ Landscape } & AS-8 To experience the landscape. \\
& AS-17: Fascinated by scenery. \\
& AS-20: Hoping to see magnificent vistas. \\
& AS-9: To see unusual wildlife like narwhales and polar bears. \\
\multirow{3}{*}{ Wildlife } & AS-16: . . the chance to see wildlife found nowhere else in the world. \\
& AS-4: Seeing unique wildlife of the Arctic. Interested in birds and their birthing places in the Arctic. \\
& Q-84: Iconic animals. \\
\hline \multirow{3}{*}{ Exploring } & AS-7: To be able to reach remote communities. \\
new places & AS-17: Do something interesting and different; I like to go to the end of the road kind of thing. \\
\cline { 2 - 3 } & AS-31: We normally don't take or like cruises but this is the only practical way to see the Canadian \\
& north. One of the few areas in Canada and the USA that we have not explored. \\
\hline \multirow{3}{*}{ Learning } & Q-45: I want to learn about the Arctic because I am Canadian and if we claim sovereignty over it I \\
& should have some knowledge about it. \\
\cline { 2 - 3 } & Q-48: To learn about cultural history of the Inuit people. \\
& $\begin{array}{l}\text { Q-76: I am excited to learn more about our Canadian Arctic ecology. } \\
\text { Q-82: My first choice for travel is always a new experience, one where I am learning every day. }\end{array}$ \\
\hline
\end{tabular}

Cruisers were motivated not only to experience the novelty of the landscape, but also to simply experience novelty. Common across all participants was a desire to experience a new place. This is identified in responses such as: "Do something interesting and different; I like to go to the end of the road kind of thing" (AS-17); "The Arctic is the only area in Canada that I have not visited" (Q-34); and "To explore a part of Canada, territory that I have not previously visited while I can still enjoy. The level of adventure required to get in/out of zodiacs, climbing, hiking, etc. to fully participate" (Q-47).

Though the cruisers were interested in seeing wildlife and landscapes, they also indicated a strong desire to learn. This is supported by responses such as: "To see and learn over 10 days" (AS-19) and: "My first choice for travel is always a new experience, one where I am learning everyday" (Q-82). Motivation to learn about a broad topic is reported: "I am excited to learn more about our Canadian Arctic ecology" (Q-76). One respondent had specific interest in "being with resource staff that can educate me regarding plants" (Q-117).

\subsection{Semi-Structured Interview}

During the semi-structured interview, the researcher asked, "Could you share with me your reasons for taking an expedition cruise to the Arctic?" Seeing or experiencing the landscape as a motivation was apparent again. These one-on-one verbal responses correspond to the top motivation categories identified earlier, and they reveal deeper motivations, reflective of the cruisers' aspirations and life dreams.

Cruisers talked about seeing and learning about the Arctic-the landscapes and wildlife. These themes are supported with comments such as the "landscape was a motivation of mine to go to the Arctic and certainly had a connection with nature while I was up there. To see polar bears where they live and how they live" (AM-13). This is further identified when another participant shared "I think it was always something I wanted to do because I was drawn to the beauty of the north and felt a connection to it" (CA-12). The strength of the many affective responses- "I have been interested in going to the Polar Regions since I was a child", "we've gotta see this", "I was drawn to the beauty" (AC-14) - are evidence of the depth and meaning of the expedition experience to these cruisers.

Q2. What on-ship cruising activities is the expedition company offering to meet presumed cruisers' educational expectations?

Expedition cruisers seek educational opportunities, specifically regarding the Arctic landscape. The expedition cruise company responds to these expectations by providing a diverse educational program with many opportunities for cruisers to engage. 


\subsection{Expedition Guides}

The expedition company always hires a geologist, archaeologist, marine biologist, naturalist, culturalist, historian, and photographer. All of the guides have formal and informal education relating to their area of specialization and a personal connection to the Arctic region ranging from 10 to 55 years. As an indication of the high level of their expertise, all 15 on board had university degrees, including three with PhDs and four with Master's degrees, with an average of 26 years' experience.

\subsection{Planned Educational Programming}

With the option to attend a variety of the educational presentations and the ability to interact with guides throughout the 15-day expedition, the cruisers were able to draw upon the knowledge of the guides to address their educational expectations.

The activities offered by the expedition company covered a wide range of Arctic topics, including history and culture; geography and landscape; and environment and wildlife. Most programming was offered on board during one-hour sessions presented by an experienced guide. Off-ship experiences were longer, typically 2 to $3 \mathrm{~h}$, in which cruisers took part in a range of activities often relating to the most recent one-hour presentation.

The ship made several stops at natural sites with no human presence. Cruisers were offered the opportunity to go on a guided hike according to their level of fitness. Locations for hiking were selected based on likelihood of unique wildlife viewing, known Inuit archaeology and/or European explorer history sites, and stunning landscapes. Observing plants, rocks, animal tracks, droppings, and bones was usually guaranteed.

Visits to Arctic communities consisted of guided walks with stops at the school gymnasium or cultural centre for drum dancing and throat singing presentations, Arctic games demonstrations, traditional Inuit fashion shows, and country food tastings. There were also opportunities to visit museums and historical sites. While exploring, cruisers had the chance to see plants, birds and marine creatures, and enjoy magnificent views.

The majority of the cruisers attended the daily recap held by the guides. During the one-hour meeting, the events of the day were discussed and plans for the following day were presented. This was followed by a few fun facts shared by the guides and photos taken throughout the day.

In total, over the 14-day trip, $88 \mathrm{~h}$ of formal educational programming were provided to the cruisers. On average (excluding the arrival and departure days), there were $6.5 \mathrm{~h}$ of formal programming offered per day. The $88 \mathrm{~h}$ were allocated to on-ship presentations, workshops, briefings, and recaps. There was a change in the itinerary due to heavy ice, which resulted in two full consecutive days of only onboard programming. As planned, one full day sailing across the Davis Strait was allocated for onboard programming. The remaining $44 \mathrm{~h}$ of programming were provided during off-ship excursions.

Q3. Do on-ship cruising activities for cruisers correspond to pre-cruise motivations?

\subsection{Cruiser Interaction with the Educational Programming}

Assessing the attendance of educational activities provided information about the cruisers' behaviours. We found that attendance was highest at activities that corresponded to the general cruisers' pre-cruise motivations: learning about a new place, its landscape and wildlife.

The landings and Zodiac cruises were well-attended. On any given excursion, between two and 10 of the 82 cruisers opted out. A resource staff shared "They are at them, most of them are going ashore, on the zodiac rides, despite some pretty terrible weather." (CG-03). The recap and briefings at the end of each day were well attended; participation was consistently in the high $70 \%$ range. Presentation attendance varied depending on topic and ranged from the mid 50\% range to the high $70 \%$ range. There does not appear to be a correlation between the presentation or workshop topic and the number of participants. Several workshops were offered concurrently to allow cruisers' a variety of 
options that appealed to different interests. Some workshops had limited space or a maximum number of cruisers. "What I see in our passengers in general is that for a variety of reasons they are lifetime learners, really motivated, want to get the most out of everything, the vast majority of them will attend every lecture and will make every landing. We've got older people who had extremely full days in the outdoors and what have you and they are still up for whatever social programming we are having so this is a group of people who know how to most out of life and are really keen to do that. Whatever the lecture topics are they are keen to learn for the first time or learn to a deeper knowledge." (DN-01).

Based on participant observations, some cruiser behaviours did not correspond to the identified pre-cruise motivations. These exceptions were likely due to cruisers' age, physical mobility and energy levels. Some days the weather was challenging and cruisers chose to remain on the ship instead of disembark. Of note, there were two cruisers who chose to only disembark at a single location, remaining on board the ship for the remainder of the trip. The cruisers choosing not to partake in a landing was puzzling to the guides as the cruisers' were paying a significant amount of money to "be here". One guide shared in the semi-structured interview: "When would they be back here? Never! Why not bundle up and go for a bit?" (DR-07).

\subsection{Questions Posed during Lectures}

The vast majority of the questions posed by cruisers during or after presentations (see Supplemental material) were comprehension-based. The cruisers were using the information presented to ask further questions such as "What causes polynya?" and "How does the fox avoid becoming food for the polar bear, since they follow behind?" Comprehension questions can be found across all topics presented, including climate change, wildlife, and geography. The "application" questions that cruisers asked included: "With El Niño pushing the jet stream, could that have an effect (on the climate)?" and "How will climate change impact the vegetation (in the Arctic)? More bugs? Wildfires?"

Climate change was important to many cruisers, as indicated by the open-ended survey and interview responses. Many of the cruisers connected their experiences during the expedition with the onboard presentations to gain a better understanding. There were no questions asked during the presentations that would be considered analysis or synthesis. There were several opportunities for informal learning during meals, unscheduled time on board, and zodiac rides.

\subsection{Cruiser Engagement as Reported by Expedition Guides}

To gain a deeper understanding of cruisers' behaviour on ship, the researcher asked the guides for their observations. The comments from guides show further evidence of the cruisers' interest in learning and absorbing all that the expedition itinerary had to offer. This was reinforced by comments from guides that support cruiser behaviours such as asking questions, attending presentations, and participating in activities despite the weather. "I've had some keeners that have been veracious in terms of asking questions and consuming new knowledge, that's always great" (CH-06) and "There has been great attendance at all of the presentations, they are at the recaps, sometimes people are bailing on the recaps but they are at them. Most of them are going ashore, on the zodiac rides, despite some pretty terrible weather" (CG-03). Another guide refers to the cruisers' desire to learn more about a specific area: "I feel like the people in this group are a bit more serious about learning. There is usually a small general interest in plants and there are a half dozen that are really keen" (CM-05). Another guide mentioned the overall attitude and engagement of the cruisers, "On this trip there is no one who is down, they are a very bubbly, happy, engaging group of folks" (MM-04).

The cruisers' motivations are further supported by the following comments from the guides. "What I see in our passengers in general is that for a variety of reasons they are lifetime learners, really motivated, want to get the most out of everything. The vast majority of them will attend every lecture and will make every landing. You know, we even saw, late in the evening we've got older people who had extremely full days in the outdoors and what have you and they are still up for whatever social 
programming we are having. So this is a group of people who know how to get most out of life and are really keen to do that" (DN-01).

Another guide touched on the continued motivation to learn and behaviours during informal times on ship, "They are all really great. They are motivated to learn, and every day, all through the trip, the lecture hall has been pretty much full. And I'm really impressed, everybody comes away from the lecture super charged and enthusiastic, tons of questions, not just after the lecture, but as they interact with us out on the land, over dinner, in the hallways, it's a very high level of enthusiasm" (RB-02).

The expedition cruisers' behaviours on ship correspond to pre-cruise motivations. The cruisers are keen to be immersed in this novel destination and to take it all in despite some unpleasant weather. They interact with the guides to gain more knowledge about the wildlife and landscape.

Q4. What is the impact of the educational experiences on post-cruise attitudes?

\subsection{Arctic Knowledge}

Participants were asked questions concerning their general knowledge of the Arctic environment. Note that the pre and post-trip surveys were not linked by participant. In the pre-trip survey $(n=144)$, high scores were achieved by only $2 \%$ of respondents, who answered 12 of 15 questions correctly. The mean score of the pre-trip participants was 5.9 correct answers and shows an even distribution of answers with a median score of $6 / 15$. Six percent of respondents were only able to manage one correct answer.

The same questions were asked in the post-trip survey $(n=92)$. While the subject matter of the questions was not necessarily addressed during the expedition, scores improved. One participant achieved a perfect score. The post-trip survey mean score for all participants increased by 0.6 points to 6.4 and the median value improved by 2 points to $8 / 15$. Those who could only manage a single correct answer were reduced to only $2 \%$ of participants.

There was a statistically significant difference in the scores for pre-cruise $(M=5.9, S D=3.1)$ and post-cruise $(M=7.5, S D=2.9)$ conditions $\left(t_{234}=4.5, p<0.001\right)$. The overall average increased by $10 \%$, as cruisers answered one to two more questions correctly in the post-trip survey. In particular, there were six questions where performance increased significantly. Questions \#1 on climate, \#4 on culture, $\# 10$ on human history, $\# 11$ and $\# 12$ on geography and \#13 on oceanography (see Figure 1). This quiz was assembled pre-season; therefore, it was not guaranteed that the content of questions would be addressed during the expedition, making this result even more significant. Results suggest that there is an increase in knowledge that occurs after participation in an Arctic expedition.

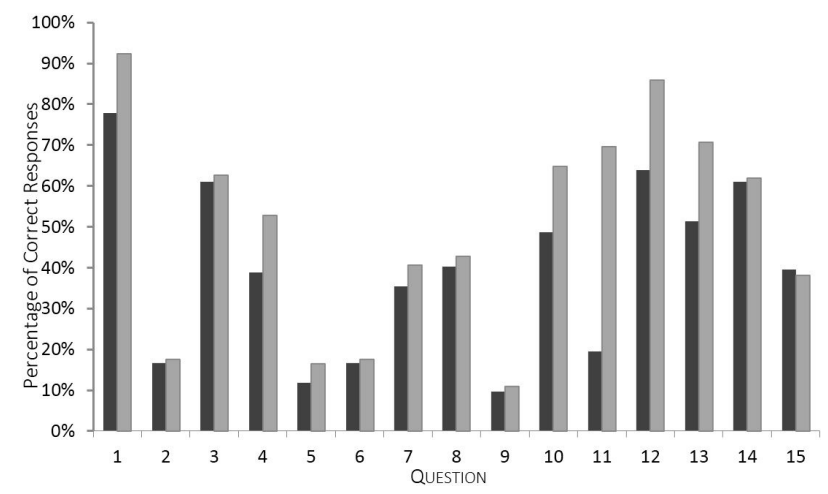

Figure 1. Results of pre-trip (dark grey bars) and post-trip (light grey bars) survey response by question.

\subsection{Self-Reported Knowledge Gain}

To better understand the participants' view on potential educational benefits from participation in an Arctic expedition, they were asked: "Please indicate how much you think this trip has increased 
your knowledge in the areas listed below", using a Likert scale with " $5=$ A great deal" and " $1=$ none" (see Table 4).

Table 4. Percent distribution of cruisers' self-reported knowledge gain by topic $(n=92)$.

\begin{tabular}{ccccccc}
\hline & $\begin{array}{c}\text { Mean } \\
\text { (of 7) }\end{array}$ & A Great Deal & $\begin{array}{c}\text { A Moderate } \\
\text { Amount }\end{array}$ & Somewhat & A Little Bit & None \\
\hline General awareness of the natural environment & 4.6 & 65.6 & 30.1 & 3.2 & 1.1 \\
\hline Natural History & 4.31 & 40.9 & 48.4 & 8.6 & 1.1 & 1.1 \\
Environmental conservation & 4.3 & 43 & 46.2 & 8.6 & 2.2 & 0 \\
Marine Biology \& Oceanography & 3.8 & 15.1 & 54.8 & 3.5 & 1.1 \\
Ornithology (Bird biology) & 3.59 & 11.8 & 44.1 & 1.1 \\
\hline
\end{tabular}

The post-trip participants indicated that their knowledge gain about the natural environment was high. Natural history and environmental conservation followed closely behind. However, the more science-related topics such as marine biology and oceanography had lower scores. Therefore, participants learned a moderate to high amount in three areas: general awareness of the natural environment, natural history, and environmental conservation. Combining these data with the results from the "knowledge of the Arctic" section suggests there was a positive impact on expedition cruiser knowledge.

\subsection{Knowledge Gain Reported by Cruisers}

To more fully understand the impact of educational experiences offered by the expedition cruise company, an open-ended question in the post-trip survey $(n=92)$ asked: "Has the expedition to the Arctic had an impact on you? Please explain". Supporting the quantitative findings, responses indicated that the cruisers made gains in general knowledge. Responses such as: "Gives me more knowledge of the world around us" (PS-04), and "We very much appreciated the interaction with the staff and high educational quality of lectures and sharing of knowledge" (PS-64).

Arctic-specific knowledge as indicated by: "Expanded knowledge and appreciation of that part of the world" (PS-59), "Increased knowledge about the Arctic" (PS-32), "Greater understanding of the eastern coast of Canada and the people and wildlife that inhabit it" (PS-16), and one respondent shared "Definitely! Since the expedition I have been reading about the Arctic, listening to discussions and watching video. Because I am more knowledgeable, I have more interest in and am more concerned about the issues affecting the environment, the wildlife and the Inuit way of life. I feel a personal connection to the Arctic. I have a better understanding of the impact of global warming on the Arctic environment and certainly on the people living there. I have also stayed loosely connected with some of the people that I met on the voyage. It is all such a positive memory, a once in a lifetime experience" (PS-58).

Responses also indicated an increase in knowledge about climate change: “This trip reinforced my views on Global warming as a very big problem" (PS-41), and "Made even more aware of climate change" (PS-54). "Instilled a better awareness of the negative effects of human activities that pose a threat to the balance of nature (animal and environmental) throughout the globe" (PS-55).

Knowledge gain regarding the Inuit culture was outside the scope of this research. However, responses on this topic did surface: "Gave me a much better understanding of issues regarding the Inuit" (PS-19), and: "A greater understanding of Arctic communities and culture" (PS-44), "Have a better understanding of the difficulties of the local residents and the Northern Nutrition program, which has had a lot of negative publicity lately, needs review at a high level (we did some window shopping/pricing in the Northern store)" (PS-64).

\subsection{Attitudes about Arctic Resource Management}

Prior to departure on the itinerary, cruisers agreed with many of the environmental resource statements. However, their agreement increased further after the trip (see Table 5). Although support 
for all conservation measures included in the survey received a high level of support, responses to questions \#1 and \#9 indicated that cruisers became more supportive of conservation measures that limit the activities of future tourists in the Arctic. The category of "no opinion" was selected 5.7\% of the time pre-trip. This decreased to $0.7 \%$ in the post-trip survey, showing an over $90 \%$ decrease of "no opinion" responses.

The results suggest that participation in an Arctic expedition had only a slight impact on cruiser attitudes toward environmental and management issues facing the Arctic. However, when interpreting the results, consideration should be given to the low number of "no opinion" responses and respondents' high base level of agreement with these issues.

Table 5. Attitudes toward Arctic resource management pre- and post-survey.

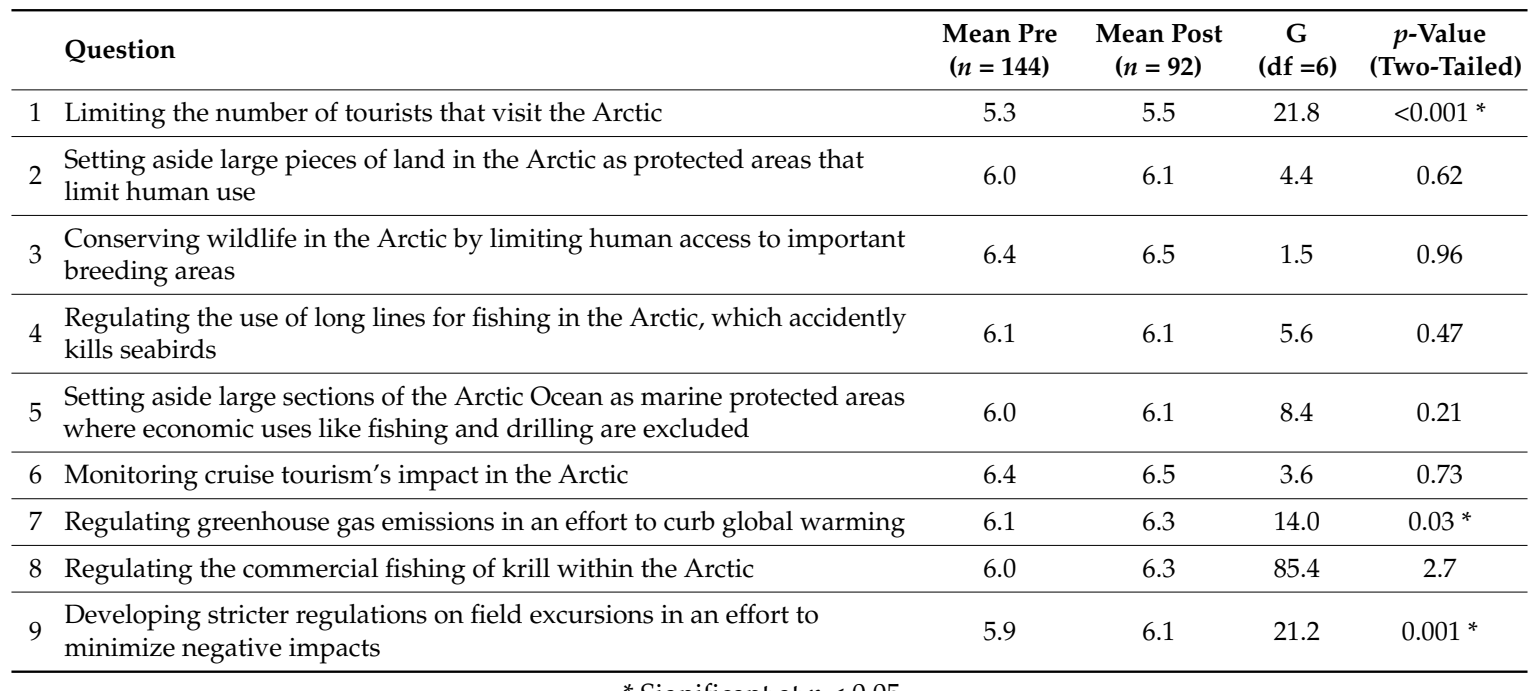

* Significant at $p<0.05$.

\subsection{General Views about the Natural Environment}

Similar to the responses about Arctic resource management, the pre-trip survey indicated strong opinions that became even more pronounced after the trip (see Table 6). Comparing answers from the pre- and post-trip surveys to questions \#2, \#6, \#11, and \#12 more closely, the respondents' attitudes regarding the environment shifted by the conclusion of the trip. Question \#2, addressing a spiritual connection, showed significant change post-cruise, with no participant indicating "no opinion", and a $16 \%$ increase in those who felt a stronger connection with nature. Over $20 \%$ more participants indicated post-trip that they strongly agree that seeing the physical grace of a whale conveys to them a sense of the beauty of the natural world. There was also a significant increase in how participants felt about their relationship to wildlife in the Arctic, with $16.5 \%$ more participants indicating a stronger connection.

Question \#13 looked at the level of agreement that participants had with the expedition company's mandatory Discovery Fee of US\$250. Prior to the trip, 43.8\% of participants indicated that they strongly agree with a fee that is used to support environmental efforts to the areas visited. About 5\% of participants did not have an opinion. However, the post-trip survey shows that $64.5 \%$ of participants thought of the Discovery Fee favourably and the number of those with no opinion of the fee dropped to zero.

An overall pattern that emerges from the responses is a deeper connection to nature and an interest in learning more about the wildlife and environment. The items that showed a statistically significant increase related back to cruiser motivations. After experiencing the Arctic first-hand the participants indicated support for the protection of the Arctic environment in the form of stricter visitor guidelines and monetary fees to assist with restoration. 
Table 6. Pre-trip and post-trip comparison of general views toward the natural environment.

\begin{tabular}{|c|c|c|c|c|c|}
\hline & Question & $\begin{array}{c}\text { Mean Pre } \\
(n=144)\end{array}$ & $\begin{array}{l}\text { Mean (Post) } \\
\quad(n=92)\end{array}$ & $\begin{array}{c}G \\
(\mathrm{df}=6)\end{array}$ & $\begin{array}{c}p \text {-Value } \\
\text { (Two-Tailed) }\end{array}$ \\
\hline 1 & I enjoy the thrill of sailing across a wild place like the Davis Strait & 5.76 & 6.31 & 37.5 & 1.41 \\
\hline 2 & I don't have a particularly strong spiritual connection with nature & 3.03 & 2.58 & 29.5 & $<0.001 *$ \\
\hline 3 & I approve of seal hunting for aboriginal subsistence & 5.72 & 6.14 & 15.7 & $0.015^{*}$ \\
\hline 4 & $\begin{array}{l}\text { If large oil reserves are found in a wildlife refuge, I believe drilling should be approved so long as } \\
\text { efforts are made to protect the environment }\end{array}$ & 3.16 & 3.03 & 2.0 & 0.92 \\
\hline 5 & I am not particularly interested in bird-watching & 3.1 & 3.17 & 4.8 & 0.57 \\
\hline 6 & Seeing the physical grace of a whale conveys to me a sense of the beauty of the natural world & 6.1 & 6.43 & 25.1 & $<0.001$ * \\
\hline 7 & I am morally opposed to the hunting of seals for sport & 5.53 & 5.54 & 7.7 & 0.26 \\
\hline 8 & $\begin{array}{l}\text { I can accept the harvesting of a small number of unthreatened animal species in fishing nets if it } \\
\text { keeps the price of fish at a reasonable price for consumers }\end{array}$ & 4.08 & 4.4 & 22.8 & $<0.001$ * \\
\hline 9 & $\begin{array}{l}\text { I think the environment is important but protection measures should not hurt the local or } \\
\text { national economy }\end{array}$ & 3.2 & 3.28 & 7.5 & 0.27 \\
\hline 10 & I would enjoy reading a book on the ecology of the Arctic & 5.28 & 5.78 & 26.1 & $<0.001 *$ \\
\hline 11 & I feel a strong connection with the wildlife that I see & 5.59 & 6.08 & 23.9 & $<0.001$ * \\
\hline 12 & I participate in tours like this one primarily to see beautiful scenery and wildlife & 6.06 & 6.43 & 16.5 & $0.01 *$ \\
\hline 13 & I support the expedition company's $\$ 250$ fee for restoration and protection of the Arctic environment & 6.2 & 6.56 & 23.2 & $<0.001 *$ \\
\hline 14 & Mandatory visitation guidelines are needed for the protection of the Arctic environment & 6.28 & 6.42 & 3.6 & 0.73 \\
\hline 15 & $\begin{array}{l}\text { While approaching a group of muskoxen to photograph them, they show signs of agitation. As long } \\
\text { as they don't run, it is okay to photograph before moving away }\end{array}$ & 3.25 & 3.68 & 11.9 & 0.07 \\
\hline 16 & $\begin{array}{l}\text { In order to get a better photo of the sleeping walrus, it is acceptable to toss a small stone or make a } \\
\text { noise to awaken the walrus }\end{array}$ & 2.08 & 2.15 & 4.1 & 0.67 \\
\hline 17 & Visitors to the Arctic should follow the guidelines designed to protect the wildlife and vegetation & 6.48 & 6.8 & 19.5 & $0.003 *$ \\
\hline
\end{tabular}

* Significant at $p<0.05$. 


\subsection{Attitude Change Reported by Cruisers}

The open-ended question in the post-trip survey asked: "Has the expedition to the Arctic had an impact on you? Please explain." Many of the responses show a reinforcement of pre-trip attitudes. The common theme found in the responses that support their attitudes regarding the Arctic environment was indicated by: "Yes, it reinforced my appreciation for this part of Canada and the need to preserve it" (PS-08), "I enjoy the north country, the landscape is unlike other parts of the world. Seeing the strength and at the same time the fragility of the country, makes me more aware of why everyone needs to become stewards of this great land" (PS-17), "It has given me a greater appreciation of the 'wild areas' that are still left on our planet. The great solitude of the Arctic is a precious resource that we cannot waste" (PS-35), and "Have an even greater concern about the environment in terms of energy, waste, and disposal of products of our consumer society" (PS-38).

There were also a few responses noting the connection with the natural environment and Inuit culture: "the importance of restricting commercial exploitation without negatively affecting the aboriginal population's ability to do more than just survive" (PS-46) and "Yes, I am more appreciative of the fragile environmental impact of global warming, and natural resource explorations and its impact on the land and its people" (PS-60).

The strong baseline of attitudes reported in the pre-trip survey align with cruisers' post-trip attitudes toward the environment.

\subsection{Behaviours}

Participants expressed a slight increase in some environmentally-oriented behaviours (Table 7). Prior to the cruise, there was already a high level of engagement in the nine items identified on the survey. Results indicated that participants modified their behaviours in ways that showed a new interest in donating time or money to an organization, attending meetings in the community about the environment, or voting for elected officials that support environmental protection. However, these behaviours most likely would not influence daily activities that influence, for example, consumer decisions.

Table 7. Comparison of pre-trip and post-trip behaviours.

\begin{tabular}{|c|c|c|c|c|c|}
\hline & Question & $\begin{array}{c}\text { Mean Pre } \\
(n=144)\end{array}$ & $\begin{array}{c}\text { Mean Post } \\
(n=92)\end{array}$ & $\begin{array}{c}G \\
(\mathrm{df}=9)\end{array}$ & $\begin{array}{c}p \text {-Value } \\
\text { (Two-Tailed) }\end{array}$ \\
\hline 1 & $\begin{array}{l}\text { Donating money or time to organizations } \\
\text { concerned with the protection and restoration of } \\
\text { the Arctic }\end{array}$ & 2.62 & 2.87 & 19.4 & $<0.001$ * \\
\hline 2 & $\begin{array}{l}\text { Voting for elected officials that support } \\
\text { environmental protection }\end{array}$ & 3.68 & 3.9 & 10.9 & 0.03 * \\
\hline 3 & $\begin{array}{l}\text { Becoming a member of organizations concerned } \\
\text { with the environment }\end{array}$ & 3.19 & 3.15 & 3.9 & 0.42 \\
\hline 4 & $\begin{array}{l}\text { Avoiding the use or purchase of certain products } \\
\text { because of their environmental impact }\end{array}$ & 3.88 & 4.01 & 3.6 & 0.46 \\
\hline 5 & Contributing waste to a recycling program & 4.71 & 4.84 & 7.3 & 0.12 \\
\hline 6 & Making efforts to reduce your consumption & 4.45 & 4.35 & 27.6 & $<0.001 *$ \\
\hline 7 & Finding ways to reuse materials & 4.38 & 4.41 & 1.5 & 0.83 \\
\hline 8 & Reading about the environment & 4.01 & 3.96 & 0.9 & 0.92 \\
\hline 9 & $\begin{array}{l}\text { Attending meetings in the community about } \\
\text { the environment }\end{array}$ & 2.9 & 3.24 & 10.4 & 0.03 * \\
\hline
\end{tabular}

* Significant at $p<0.05$. 


\section{Discussion}

The increase in cruise tourism within the last decade, especially within Canada's Arctic Region, has created a demand for better understanding of how cruisers' attitudes toward the environment are affected as a result of their expedition experiences. This will help inform the debate on whether there is value in supporting a tourism industry in an ecologically sensitive region. We examined cruiser motivations to take an Arctic expedition to determine whether the educational programing had any impact on cruiser knowledge, attitudes, or behaviour.

Pro-environmental attitudes of cruisers can be positively affected by the incorporation of well-designed educational programming $[29,35,39,40]$. There has been debate, however, regarding the effectiveness of knowledge transfer within nature-based tourism [41]. In a cruise context, this is because it has been hypothesized that a cruiser's motivation to take a cruise is based upon seeking relaxation and comfort and is therefore at odds with focused learning. Regardless of the intentionality of the educational programming, it may have little to no lasting effect on attitude or behavioural change toward the environment.

The first question of this study assessed if motivational factors for engaging in Arctic expedition cruising differed from motivational factors for mainstream cruising. Our results indicated that expedition cruisers are motivated by opportunities to learn. Specifically, expedition cruisers are motivated to gain a deeper understanding of the unique landscape and wildlife found in the Arctic. Our results also indicated that cruisers are eager to experience the novelty associated with visiting the Arctic. Therefore, expedition cruisers have different motivations compared to those that travel on a mainstream cruise line to Caribbean-type destinations. It is therefore highly likely that they also have different expectations of the cruise company, the programming, the comfort of the accommodations, and of the excursions.

According to the ELM, the results indicated that expedition cruisers are in the first stage of central processing. The expedition cruiser was motivated to think about the message that is being conveyed, as evidenced by the open-ended survey responses. For example: "My first choice for travel is always a new experience, one where I am learning everyday" (Q-82), "I am excited to learn more about our Canadian Arctic ecology" (Q-76), and "Being with resource staff that can educate me regarding plants" (Q-117).

Expedition cruisers already have a high level of environment-related knowledge and engagement in pro-environmental behaviours, indicating that they likely have the ability to process the information being presented on-ship as it complements their prior knowledge. This is an important result because the central route of persuasion strengthens a change in attitude [42].

The ELM further suggests that if the educational program is designed properly, with a clear message, is well-presented, and is meaningful to the cruiser, it is likely that s/he will have a high level of cognitive involvement. Our results indicated that the expedition company is providing a meaningful and intentional educational program to the cruisers. Over the 15-day trip there was on average $6.5 \mathrm{~h}$ per day of planned educational programming and the expedition company's knowledgeable, interactive, and enthusiastic guides provided interesting lectures that appealed to cruisers' interests and learning expectations. In addition, cruising is conducive to continued or repeated exposure as cruisers are immersed in pro-environmental messaging for the duration of the Arctic trip. This further supports the likelihood of change in attitudes as there is a combination of immersive nature-based experience, information from guides, and relevant educational activities. An important aspect of central processing and long-lasting change in attitudes is the opportunity to contemplate the information being provided. Hiking or sitting on outer decks to enjoy the view are just two examples of activities that provided the cruisers with the opportunity and sufficient time for careful reflection of the messages provided.

Our results indicated that cruisers' pro-environmental attitudes strengthened from pre-trip to post-trip. The participants' knowledge of the Arctic region increased on several of the questions, in particular those related to geography and climate and culture and history. There was very little improvement in the biology- and science-focused questions, though the cruisers self-reported 
a large increase in their general awareness of the natural environment, natural history, and environmental conservation.

Attitudes about Arctic resource management issues showed a slight increase in stronger opinions. However, consideration should be given to the cruisers' high base level of agreement toward resource management and the Arctic environment in general. Open-ended interview responses also indicated a reinforcement of attitudes. For example, "this trip reinforced my views on global warming as a very big problem" (PS-41) and "it reinforced my appreciation for this part of Canada and the need to preserve it" (PS-08).

After traveling to the Arctic, participants indicated a positive change in some behaviours. More money or time were donated to organizations concerned with the protection and restoration of the Arctic, and participants indicated that they have a stronger belief that voting for elected official that support environmental protection is important. Given the profile of this study's expedition cruisers, these behaviours and level of engagement with environmental issues was already quite high. The fact that any changes in behaviour were documented post-trip is, therefore noteworthy and suggests that educating less informed group of cruisers (i.e., mainstream cruisers) could have a greater influence on behaviour. These results are similar to Walker and Moscardo's (2006) results on expedition cruising in Australia [21]. They noted that attitude change increases when there is a combination of immersive nature-based experience, information provided from the field staff, and activities offered through educational programming.

With an increase in cruise tourism to Canada's Arctic region comes a need to better understand the cruise experience and its long-lasting impacts. To the authors' knowledge, this is the first quantitative and qualitative study addressing cruiser motivations to take an expedition cruise in the Polar regions, and one of few to study the impact of educational programming on cruisers' attitudes toward environmental conservation.

From a managerial perspective, cruise companies can benefit from this research by gaining market insights. Customer retention is important and Arctic expedition cruisers who value environmental programming are likely to make informed choices in the future, due to the high expenditure of time and money spent on the Arctic expedition.

The data collected from this study indicated that expedition cruising currently caters to a narrow demographic with a specific motivation to learn and an already high level of engagement in environmentally conscious behaviours. Recently, a mainstream cruise company has begun operating in the Arctic Regions of Canada, offering a Northwest Passage cruise for 32 days from Alaska to New York with 1080 passengers. They are catering to the comfort- and kinship-motivated mainstream cruiser by providing a variety of entertainment options on board and offering select off-ship activities [43]. While in the Arctic Region (26 days) the cruisers have only nine days allocated for off-ship activities as only a limited number of ports are able to accommodate a large ship. All nine stops are within communities and only two are made within Canada. It is highly unlikely that cruisers on a mainstream cruise will have the same environmentally focused knowledge and experience as those travelling on an expedition ship but the potential for knowledge transfer and encouraging behavioural changes may be higher as a result.

\section{Conclusions}

On board, expedition cruisers connect with nature, appreciate and expect knowledgeable resource staff, seek unique experiences, and engage in lectures and other educational experiences. Post-cruise, they are more knowledgeable about climate, geography, history, and culture but feel as though they are more knowledgeable about the environment, natural history, conservation, biology, and ornithology. Notably, the respondents are highly likely to continue their interest in learning about the Arctic after the trip has finished. 
This research provides valuable insight into the educational motivations of expedition cruisers. Learning opportunities are an important component of the cruise experience, which has the potential to positively impact cruiser attitude and knowledge post-cruise. These findings will encourage cruise companies to improve their educational offerings (i.e., preparedness, program quality, level of engagement) to meet the expectations of their clientele, thereby transferring critical knowledge of environmental stewardship.

Supplementary Materials: The following are available online at http:/ /www.mdpi.com/2079-9276/6/3/23/ s1, Research Ethics Certificate, Pre-cruise survey, Post-cruise survey, Semi-structured interview questions for guides, Semi-structured interview questions for cruisers, List of questions posed by cruisers during educational programing.

Acknowledgments: We would like to thank Adventure Canada for kindly allowing us to conduct research on their operation. The Northern Scientific Training Program provided an award to Brittany Manley to offset the costs of research in the North.

Author Contributions: Shoshanah Jacobs and Brittany Manley conceived on the project. Brittany Manley, Shoshanah Jacobs, and Statia Elliot designed the methodology. Brittany Manley collected the data. Brittany Manley, Shoshanah Jacobs, and Statia Elliot analysed the data. Brittany Manley wrote an MSc thesis on the topic. Shoshanah Jacobs drafted the article.

Conflicts of Interest: The authors declare no conflict of interest. Adventure Canada does not expect a right of first refusal, a preview approval of any publications, ownership, nor to set the direction of the research.

\section{References}

1. Douglas, N.; Douglas, N. Foreword. In Cruise Tourism in Polar Regions: Promoting Environmental and Social Sustainability; Earthscan: London, UK, 2010; p. xx.

2. Stewart, E.J.; Howell, S.E.L.; Draper, D.; Yackel, J.; Tivy, A. Sea Ice in Canada's Arctic: Implications for Cruise Tourism. Arctic 2007, 60, 370-380. [CrossRef]

3. Maher, P.T.; Meade, D. Cruise Tourism in Auyuittuq, Sirmilik and Quttinirpaaq National Parks; Technical Report-ORTM Publication Series 2008-02; UNBC ORTM Program: Prince George, BC, Canada, 2008.

4. Stirling, I.; Parkinson, C.L. Possible effects of climate warming on selected populations of polar bears (Ursus maritimus) in the Canadian Arctic. Arctic 2006, 59, 261-275. [CrossRef]

5. Serreze, M.C.; Holland, M.M.; Stroeve, J.C. Perspectives on the Arctic's shrinking sea-ice cover. Science 2007, 316, 1533-1536. [CrossRef] [PubMed]

6. Arntsen, A.E.; Song, A.J.; Perovich, D.K.; Richter-Menge, J.A. Observations of the summer breakup of an Arctic sea ice cover. Geophys. Res. Lett. 2015, 42, 8057-8063. [CrossRef]

7. Feng, Z.; Ji, R.; Campbell, R.G.; Ashjian, C.J.; Zhang, J. Early ice retreat and ocean warming may induce copepod biogeographic boundary shifts in the Arctic Ocean. J. Geophys. Res. Oceans 2016, 121, 1-22. [CrossRef]

8. Dawson, J.; Johnston, M.E.; Stewart, E.J. Governance of Arctic expedition cruise ships in a time of rapid environmental and economic change. Ocean Coast. Manag. 2014, 89, 88-99. [CrossRef]

9. Lück, M. Nautical Tourism: Concepts and Issues; Cognizant Communication: Putnam Valley, NY, USA, 2007; pp. 75-82.

10. Lemelin, R.H.; Johnston, M. Northern protected areas and parks. Parks Prot. Areas Can. Plan. Manag. 2008, 3, 294-313.

11. Dawson, J.; Stewart, E.J.; Maher, P.T.; Slocombe, D.S. Climate Change, Complexity and Cruising in Canada's Arctic: A Nunavut Case Study. In Natural Resources and Aboriginal People in Canada, 2nd ed.; Anderson, R., Bone, R.M., Eds.; Captus Press Inc.: Concord, ON, Canada, 2009; pp. 414-439.

12. Lemelin, H.; Dawson, J.; Stewart, E.J.; Maher, P.; Lück, M. Last-chance tourism: The boom, doom, and gloom of visiting vanishing destinations. Curr. Issues Tour. 2010, 13, 477-493. [CrossRef]

13. Lück, M.; Maher, P.T.; Stewart, E.J. Cruise Tourism in Polar Regions: Promoting Environmental and Social Sustainability; Earthscan: London, UK, 2010.

14. Johnston, A.; Johnston, M.; Stewart, E.; Dawson, J.; Lemelin, H. Perspectives of decision makers and regulators on climate change and adaptation in expedition cruise ship tourism in Nunavut. North. Rev. 2012, $35,69-95$. 
15. Dawson, J.; Stewart, E.J.; Johnston, M.E.; Lemieux, C.J. Identifying and evaluating adaptation strategies for cruise tourism in Arctic Canada. J. Sustain. Tour. 2016, 24, 1425-1441. [CrossRef]

16. Johnston, M.; Dawson, J.; De Souza, E.; Stewart, E.J. Management challenges for the fastest growing marine shipping sector in Arctic Canada: Pleasure crafts. Polar Rec. 2016, 53, 1-12. [CrossRef]

17. IAATO (International Association of Antarctica Tour Operators). Tourism Overview. 2013. Available online: http:/ / iaato.org/tourism-overview (accessed on 20 May 2017).

18. Jones, C.S. Arctic ship tourism: An industry in adolescence. North. Raven 1999, 13, $28-31$.

19. Marsh, J.; Staple, S. Cruise tourism in the Canadian Arctic and its implications. In Polar Tourism: Tourism and the Arctic and Antarctic Regions; Hall, C.M., Johnston, M.E., Eds.; John Wiley and Sons Ltd.: Chichester, UK, 1995; pp. 63-72.

20. Maher, P.T.; Stewart, E.; Lück, M. Moving forward. In Cruise Tourism in Polar Regions: Promoting Environmental and Social Sustainability; Earthscan: London, UK, 2010; pp. 227-232.

21. Walker, K.; Moscardo, G. The Impact of Interpretation on Passengers of Expedition Cruises. In Cruise Ship Tourism; Dowling, R.K., Ed.; CABI: Wallingford, UK, 2006; pp. 105-114.

22. Green, G. Students on Ice: Learning in the Greatest Classrooms on Earth. In Cruise Tourism in Polar Regions: Promoting Environmental and Social Sustainability; Earthscan: London, UK, 2010; pp. 93-105.

23. Snyder, J.; Shackleton, K. Ship in the Wilderness; Dent and Sons: London, UK, 1986.

24. Hung, K.; Petrick, J.F. Why do you cruise? Exploring the motivations for taking cruise holidays, and the construction of a cruising motivation scale. Tour. Manag. 2011, 32, 386-393. [CrossRef]

25. Jones, R.V. Motivations to cruise: An itinerary and cruise experience study. J. Hosp. Manag. Tour. 2011, 18, 30-40. [CrossRef]

26. Petrick, J.F. The role of quality, value, and satisfaction in predicting cruise passengers' behavioral intentions. J. Travel Res. 2004, 42, 397-407. [CrossRef]

27. Li, X.R.; Petrick, J.F. Examining the antecedents of brand loyalty from an investment model perspective. J. Travel Res. 2008, 47, 25-34. [CrossRef]

28. Petrick, J.F. Are loyal visitors desired visitors? Tour. Manag. 2004, 25, 463-470. [CrossRef]

29. Ham, S. From interpretation to protection: Is there a theoretical basis? J. Interpret. Res. 2009, 14, 49-57.

30. Petty, R.E.; Cacioppo, J.T. The Elaboration Likelihood Model of Persuasion; Springer: New York, NY, USA, 1986; pp. 1-24.

31. Petty, R.E.; Haugtvedt, C.P.; Smith, S.M. Elaboration as a determinant of attitude strength: Creating attitudes that are persistent, resistant, and predictive of behavior. Attitude Strength Anteced. Conseq. 1995, 4, 93-130.

32. Ellis, C.; Kriwoken, L.K. Off the Beaten Track: A Case Study of Expedition Cruise Ships in South-west Tasmania, Australia. In Cruise Ship Tourism; Dowling, R.K., Ed.; CABI: London, UK, 2006; pp. 251-260.

33. Powell, R.B.; Brownlee, M.T.; Kellert, S.R.; Ham, S.H. From awe to satisfaction: Immediate affective responses to the Antarctic tourism experience. Polar Rec. 2012, 48, 145-156. [CrossRef]

34. Stern, P.C.; Dietz, T.; Kalof, L. Value orientations, gender, and environmental concern. Environ. Behav. 1993, 25, 322-348. [CrossRef]

35. Powell, R.B.; Kellert, S.R.; Ham, S.H. Antarctic tourists: Ambassadors or consumers? Polar Rec. 2008, 44, 233-242. [CrossRef]

36. Guest, G.; Bunce, A.; Johnson, L. How many interviews are enough? An experiment with data saturation and variability. Field Methods 2006, 18, 59-82. [CrossRef]

37. Murrant, C. Blooming 101: How to Use the Bloom's Taxonomy Metric to Assess Course Learning Expectations; University of Guelph: Guelph, ON, Canada, 2014.

38. Dillman, D.A. Mail and Internet Surveys: The Tailored Design Method; Wiley: New York, NY, USA, 2000; Volume 2.

39. Lück, M. Education on marine mammal tours as agent for conservation-But do tourists want to be educated? Ocean Coast. Manag. 2003, 46, 943-956. [CrossRef]

40. Walter, P.G. Theorising visitor learning in ecotourism. J. Ecotour. 2013, 12, 15-32. [CrossRef]

41. Hollinshead, K. Surveillance of the worlds of tourism: Foucault and the eye-of-power. Tour. Manag. 1999, 20, 7-23. [CrossRef] 
42. Perloff, R.M. The Dynamics of Persuasion: Communication and Attitudes in the Twenty-First Century; Routledge: New York, NY, USA, 2010.

43. Crystal Cruises. Northwest Passage. Available online: http://www.crystalcruises.com/northwest-passagecruise (accessed on 10 November 2015). 